\title{
Life Cycle Cost Analysis of a Hybrid Photovoltaic/Thermal Greenhouse Dryer
}

\author{
P. Barnwal and G.N. Tiwari*
}

\author{
Centre for Energy Studies, Indian Institute of Technology Delhi, New Delhi 110 016, India
}

\begin{abstract}
In this paper, life cycle cost analysis of a self sustained hybrid photovoltaic/thermal (PV/T) greenhouse dryer has been carried out. The hybrid PV/T integrated greenhouse (roof type even span) dryer, designed and constructed at Solar Energy Park, Indian Institute of Technology, New Delhi $\left(28^{0} 35^{\prime} \mathrm{N}, 77^{0} 12^{\prime} \mathrm{E}, 216 \mathrm{~m}\right.$ above MSL), India, has been used to dry Thompson seedless grapes under forced mode of operation. The annualized cost method has been used to determine the pay back period of the hybrid PV/T greenhouse dryer. The payback period is about 1.24 to 4.63 years which is lower than the expected life of the dryer i.e. about 30 years. The effect of various parameters such as interest rate, present worth, annual cash flow etc. has also been worked out.
\end{abstract}

Keywords: Solar energy, PV/T greenhouse dryer, life cycle cost, payback period.

\section{INTRODUCTION}

In recent years, there is a global concern for the food and energy security of growing world population. For food security, either the crop production should increase or post harvest losses should reduce or both. The conventional energy sources e.g. coal, wood, oil, gas etc. should be conserved for energy security i.e. we must explore the renewable energy sources. If solar energy, one of the renewable energy sources, is effectively used for drying of crops, it will help in both food as well as energy security. This is so because, crop drying is one of the effective means for reduction in the post harvest losses by removing the excess moisture from it and thus to achieve longer safe storage period and better product quality. One of the most promising alternatives to conserve the limiting conventional energy resources is the photovoltaic (PV) applications. Depending on the mode of application, the PV applications of solar energy can provide electricity, thermal energy, daylighting etc. The forced convection crop drying is one of the areas for PV applications.

For any technology/system/enterprise, it is necessary to work out its economic viability so that the users of the technology may know the importance and can utilize the area under their command to their best advantage. Controlled environment solar drying of crops can be the most profitable in comparison with open sun drying due to better product quality and quantity and hence the attractive return.

The controlled environment solar drying is a capitalintensive technology both in terms of initial investment as well as operating cost in comparison to the traditional open sun drying. Thus, it becomes necessary that the agriculture produce from the dryer is able to not only offset the higher

*Address correspondence to this author at the Centre for Energy Studies, Indian Institute of Technology Delhi, New Delhi, 110 016, India; Tel: +91 112659 1258; Fax: +91 112658 1121/2686 2037;

E-mail: gntiwari@ces.iitd.ernet.in cost of dried product but also register adequate profits. This consideration alone should be the criteria for selection of suitable crops for controlled environment solar drying at any given geographical location. The temperature in a drying chamber should be maintained to an optimum level for a given crop for higher yield either by passive or active methods.

The life cycle cost analysis of solar dryer depends on various factors such as initial investment for construction, initial cost of additional heating (if any), operating cost, annual maintenance cost, finally annual cost of crops to be dried and life of solar dryer and its salvage value etc.

The techno-economic analysis of typical solar dryers with different kinds of energy sources has been reported [1]. The plastic and conventional solar collectors, having $560 \mathrm{~m}^{2}$ gross collector areas, to deliver useful energy of 203 $\mathrm{MWh} / \mathrm{yr}$ have been analyzed and found that the plastic solar collectors of life 5-10 years are the cheapest among all the energy systems [1].

The economic analysis of some solar dryers has been studied by methods of annual cost, annual cost per unit mass of the product and annual cost per unit useful energy [2]. The pay back period of a solar tunnel drier is 4 years for basic mode drier and 3 to 4 years for optimum mode driers [3]. On the basis of a sensitivity analysis, they showed that the design geometry was not very sensitive to minor material costs, fixed cost and operating cost. It is sensitive to costs of major construction materials of the collector, solar radiation and air velocity in the drier [3]. For a solar grain dryer incorporating photovoltaic powered air circulation, the optimum PV area to air-heater area ratio is 0.22 for a payback period of 0.5 year which is less than a year, if used to dry surplus grain for selling at the markets [4]. The potential for solar drying of selected cash crops namely tobacco, tea, coffee, grapes raisin, small cardamom, chilli, coriander seeds, ginger, turmeric, black pepper, and onion flakes etc. for Indian condi- 
tions has been estimated along with $\mathrm{CO}_{2}$ emissions mitigation [5].

A hybrid photovoltaic-thermal (PV/T) integrated greenhouse (roof type even span) dryer has been developed with the aim of crop drying using solar energy for areas, where grid electricity is not readily available such as in remote locations/areas in developing countries. This paper presents the life cycle cost analysis of the above mentioned dryer in terms of payback period, operating cost and effect of various parameters such as interest rate, present worth, annual cash flow etc. on the payback period.

\section{DESCRIPTION OF HYBRID PHOTOVOLTAIC- THERMAL (PV/T) GREENHOUSE DRYER}

A hybrid photovoltaic-thermal (PV/T) integrated greenhouse (roof type even span) dryer was developed at IIT Delhi [6-7]. The dryer has been constructed using aluminium sections (e.g. L angles, Tee-sections, flats etc.), two PV modules (glass to glass), a DC (direct current) fan and UV stabilized polyethylene sheet covering etc (Fig. 1).

The dryer has floor area of $2.50 \mathrm{~m} \times 2.60 \mathrm{~m}$ with $1.80 \mathrm{~m}$ central height and $1.05 \mathrm{~m}$ side walls height from ground. Its north and south roofs have inclinations of $30^{\circ}$ each from horizontal. Two PV modules (dimensions: $1.20 \mathrm{~m} \times 0.55 \mathrm{~m} \times$ $0.01 \mathrm{~m} ; 75 \mathrm{Wp}$ each) were integrated with a greenhouse on its south roof for thermal heating of greenhouse environment and also for providing DC electrical power to drive a DC fan under forced mode condition. A DC fan (inner diameter $=0.080 \mathrm{~m}$, outer diameter $=0.150 \mathrm{~m}$ ) has been fitted at the upper end of the east side wall to expedite the drying process to the required level by rapid removal of humid air. At bottom side, $0.15 \mathrm{~m}$ height is open and further $0.10 \mathrm{~m}$ is provided with wire mesh to provide air inlet for the greenhouse dryer. The air at bottom becomes hot and thus moves from bottom to top through a three-tier system of perforated wire mesh trays. The produce is kept on the perforated wire mesh trays. The UV stabilized polyethylene sheet has been fitted over the structural frame of the dryer with the help of steel screws with washer, rivets, nut and bolt with washer etc.

The orientation of the greenhouse dryer was east-west during the experiments, conducted for with load (drying of Thompson seedless grapes, Mutant: Sonaka) under forced mode operation in the month of April, 2007. The grapes were purchased from local market and sorted to discard the spoiled grape berries for avoiding infection to the intact grapes. To remove the undesired materials e.g. dust and foreign materials, these grapes were washed with fresh ground water and the surface water was removed by using cotton cloths and then it was placed in trays inside the greenhouse dryer for drying.

\section{THEORETICAL CONSIDERATIONS (LIFE CYCLE COST ANALYSIS)}

\section{Net Present Value $\left(\mathbf{P}_{\mathrm{NPV}}\right)$}

Let $P_{i}$ is initial investment (Rs.), $R_{m}$ is operational and maintenance expenses including repair of the fan per year (Rs.), and $R_{p}$ is UV plastic replacement cost in every five year (Rs.), $n$ is life of the dryer, $S$ is salvage value of the dryer at the end of the life (Rs.) and CF is net cash flow at the end of each year. Then, the cash-flow diagram for the dryer is given as below:

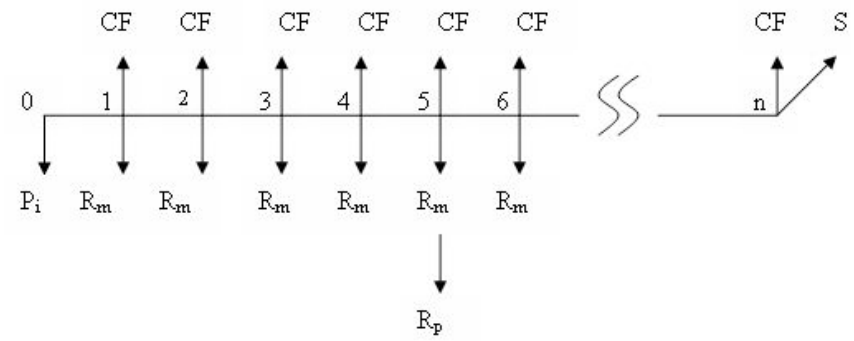

If ' $i$ ' is annual rate of interest (in fraction), then the net present value, $\mathrm{P}_{\mathrm{NPV}}$ (in Rs.) can be expressed as [8]:

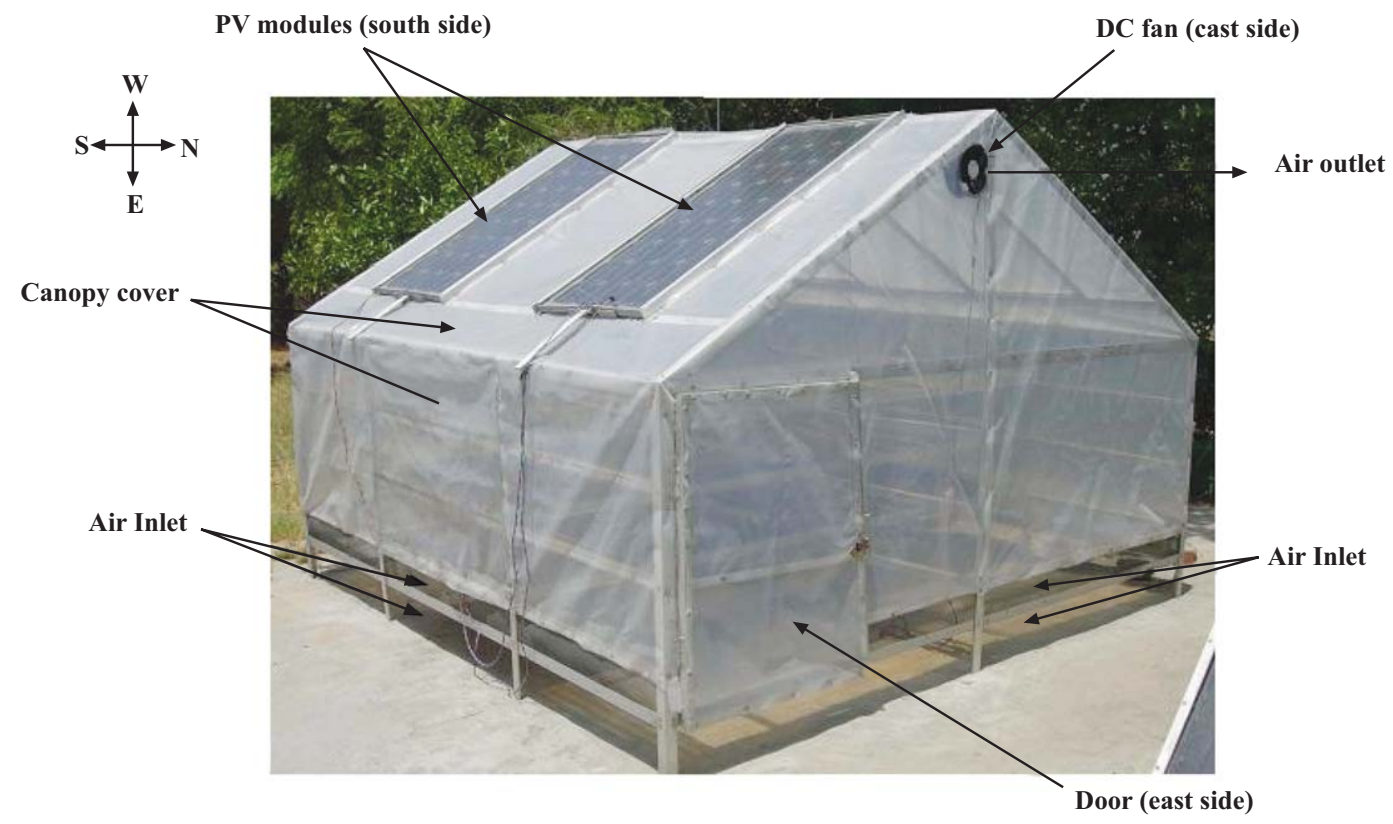

Fig. (1). Photograph of hybrid photovoltaic/thermal greenhouse dryer [6,7]. 


$$
P_{N P V}=\left[\begin{array}{l}
P_{i}+R_{m} \times\left(\frac{(1+i)^{n}-1}{i(1+i)^{n}}\right) \\
+R_{p} \times\left\{\left(\frac{1}{(1+i)^{5}}\right)+\left(\frac{1}{(1+i)^{10}}\right)+\ldots \ldots . .\right.
\end{array}\right\}
$$

For life of the system to be 30 years, the equation (1) becomes:

$$
P_{N P V}=\left[\begin{array}{c}
P_{i}+R_{m} \times\left(\frac{(1+i)^{30}-1}{i(1+i)^{30}}\right) \\
+R_{p} \times\left\{\begin{array}{l}
\left(\frac{1}{(1+i)^{5}}\right)+\left(\frac{1}{(1+i)^{10}}\right)+\left(\frac{1}{(1+i)^{15}}\right) \\
+\left(\frac{1}{(1+i)^{20}}\right)+\left(\frac{1}{(1+i)^{25}}\right)
\end{array}\right\} \\
-S \times\left(\frac{1}{(1+i)^{30}}\right)
\end{array}\right]
$$

\section{Payback Period $\left(\mathbf{n}_{\mathbf{p}}\right)$}

Payback period is the time (generally in years) required to recover the investment costs. Let us assume that net cash flow (CF) is same for each year, then net present value $\left(\mathrm{P}_{\mathrm{NPV}}\right)$ can be expressed as [9]:

$$
\begin{aligned}
& P_{N P V}=C F \times F_{R P, i, n_{p}}=C F\left[\frac{(1+i)^{n_{p}}-1}{i(1+i)^{n_{p}}}\right] \\
& \text { or, }(1+i)^{n_{p}}=\left[\frac{C F}{C F-i P_{N P V}}\right] \\
& \text { or, } n_{p}=\frac{\ln \left[\frac{C F}{C F-i P_{N P V}}\right]}{\ln (1+i)}
\end{aligned}
$$

\section{Annualized Uniform Cost, Unacost (R)}

Annualized uniform cost, Unacost $(\mathrm{R})$ is defined as the product of net present value of the system and capital recovery factor (CRF) and can be written as [8]:

$$
\begin{aligned}
\operatorname{Unacost}(R) & =P_{N P V} \times \text { Capital recovery factor }(\mathrm{CRF} \\
\operatorname{Unacost}(R) & =P_{N P V} \times F_{P R, i, n} \\
& =P_{N P V} \times\left[\frac{i(1+i)^{n}}{(1+i)^{n}-1}\right]
\end{aligned}
$$

The Capital recovery factor (CRF) can be expressed as:

$$
C R F=F_{P R, i, n}=\left[\frac{i(1+i)^{n}}{(1+i)^{n}-1}\right]
$$

If $\mathrm{M}_{\mathrm{p}}$ is the dried product output per year (in $\mathrm{kg}$ ), then cost of drying $\left(\mathrm{C}_{\mathrm{g}}\right)$ can be evaluated as:

$$
\begin{aligned}
& \text { Cost of drying } C_{g}(R s . / \mathrm{kg}) \\
& =\frac{\text { Una } \cos t, R(R s .)}{\text { Dried product output per year, } M_{p}(\mathrm{~kg})}
\end{aligned}
$$

\section{COMPUTATION PROCEDURE, RESULTS AND DIS- CUSSIONS}

It has been experimentally found that the average available energy from PV modules was $84 \mathrm{~W}$; the electrical load for forced mode operation (one DC fan) was 7-8 W and surplus energy available may be either utilized for other purposes or for larger size greenhouse dryers [6]. Thus the cost break-up for four cases ((a), (b), (c) and (d)) of the hybrid photovoltaic-thermal (PV/T) greenhouse dryer has been given in Table $\mathbf{1}$ by reducing the size of the PV module.

The initial investments $\left(\mathrm{P}_{\mathrm{i}}\right)$ for the four cases $((\mathrm{a}),(\mathrm{b}),(\mathrm{c})$ and (d)) of the dryer are Rs. 55,100, Rs. 38,750, Rs. 31,400 and Rs. 27,400 respectively (Table 1). Equations (2) and (4) has been used to compute the net present value $\left(\mathrm{P}_{\mathrm{NPV}}\right)$ and Unacost $(\mathrm{R})$ respectively for different interest rates $(4 \%, 8 \%$, $12 \%$ and $16 \%$ ) considering the life of dryer as 30 years and results are given in Table $\mathbf{2}$.

The suitable annual interest rate may be from 4 to $16 \%$ and the reasons for this are [9];

i). $\quad 4 \%$ is the subsidized rate normally offered by government sectors to promote the use of renewable energy.

ii). 7 to $7.5 \%$ is the interest rate normally offered by government banks.

iii). 10 to $12 \%$ is the rate offered by private banking sectors.

iv). 12 to $16 \%$ from any other private source.

Though the dryer is of $100 \mathrm{~kg}$ capacity for grape drying, $4.59 \mathrm{~kg}$ Thompson seedless grapes (Mutants-Sonaka) were placed in six trays inside greenhouse dryer for experimental purpose due to difficulty in handling of $100 \mathrm{~kg}$ grapes during experimentation. The drying time was 15 clear sunny days (17 days including both clear and bad weather days) of 7 hours (9:00 to 16:00 hrs) by using Hybrid PV/T integrated greenhouse dryer. Thus it requires 15 clear sunny days to dry the Thompson seedless grapes (Mutants-Sonaka) by greenhouse drying and the dried output was $28 \%$. If the capacity of the dryer has to be taken as $100 \mathrm{~kg}$, then $28 \mathrm{~kg}$ dried output (raisin) was obtained in fifteen days from drying of the grapes. The costs of raw produce (grape) and dried product (raisin) are Rs.25 per kg and Rs.150 per kg respectively, then the cash flow is Rs. $(28 \times 150-100 \times 25)$ i.e. Rs. 1700 per batch of fifteen days.

Equations (3) and (6) have been used to determine the payback period $\left(n_{p}\right)$ and cost of drying respectively for different numbers of clear days e.g. 300, 270, 240, 210 and 180 days and the results are given in Tables 3-6. 
Table 1. Cost Break-Up for Hybrid PV/T Integrated Greenhouse Dryer

\begin{tabular}{|c|c|c|c|c|c|}
\hline S. No & Item (s) & Quantity & Rate (Rs.) & Cost (Rs.) & Salvage value (Rs.) \\
\hline 1. & Aluminium sections & $79.16 \mathrm{~kg}(\approx 80 \mathrm{~kg})$ & 150.00 per $\mathrm{kg}$ & 12,000 & $24,000^{*}$ \\
\hline 2. & UV plastic sheet & $16.23 \mathrm{~m}^{2}\left(\approx 17.78 \mathrm{~m}^{2}\right)$ & 56.25 per $\mathrm{m}^{2}$ & 1,000 & 0 \\
\hline 3. & Wire mesh & $90.6 \mathrm{ft}^{2}\left(8.42 \mathrm{~m}^{2}\right)\left(\approx 100 \mathrm{ft}^{2}\right)$ & 10.00 per $\mathrm{ft}^{2}$ & 1,000 & 1,500 \\
\hline \multirow{5}{*}{4.} & \multicolumn{5}{|c|}{ PV module (glass to glass) } \\
\hline & (a) $75 \mathrm{~W}_{\mathrm{P}}$ & 2 No. & 16,350 & 32,700 & 2,000 \\
\hline & (b) $75 \mathrm{~W}_{\mathrm{P}}$ & 1 No. & 16,350 & 16,350 & 1,000 \\
\hline & (c) $35 \mathrm{~W}_{\mathrm{P}}$ & 1 No. & 9,000 & 9,000 & 500 \\
\hline & (d) $20 \mathrm{~W}_{\mathrm{P}}$ & 1 No. & 5,000 & 5,000 & 500 \\
\hline 5. & DC fan & 1 No. & 400 & 400 & 50 \\
\hline 6. & \multicolumn{3}{|c|}{ Fittings (Hinges, fasten hook of door/Kundi, Nut bolt with washer, steel screws and rivets etc ) } & 1,000 & 200 \\
\hline 7. & \multicolumn{3}{|c|}{ Labour/fabrication charges } & 7,000 & 0 \\
\hline \multirow{4}{*}{8.} & \multirow{4}{*}{\multicolumn{2}{|c|}{ Total }} & (a) & 55,100 & 27750 \\
\hline & & & (b) & 38,750 & 26750 \\
\hline & & & (c) & 31,400 & 26,250 \\
\hline & & & (d) & 27,400 & 26,250 \\
\hline
\end{tabular}

*Salvage value of aluminium is at present Rs. 80.00 per $\mathrm{kg}$ and after 30 years it will be Rs. 300.00 per $\mathrm{kg}$ for inflation rate of $4.5 \%$ per year.

Table 2. Net Present Value and Unacost of the Dryer for Thirty Years Life ( $=30$ Years)

\begin{tabular}{|c|c|c|c|c|c|c|}
\hline $\mathbf{P}_{\mathrm{i}}$ (Rs.) & S (Rs.) & $\mathbf{R}_{\mathrm{m}}$ (Rs.) & $\mathbf{R}_{\mathrm{p}}$ (Rs.) & $\mathbf{i},(\%)$ & $\mathbf{P}_{\text {NPV }}$ (Rs.) & R, (Rs.) \\
\hline \multicolumn{7}{|c|}{ Case (a) } \\
\hline \multirow{4}{*}{55100} & \multirow{4}{*}{27750} & \multirow{4}{*}{1250} & \multirow{4}{*}{1000} & 4 & 71043 & 4108 \\
\hline & & & & 8 & 68234 & 6061 \\
\hline & & & & 12 & 65477 & 8129 \\
\hline & & & & 16 & 63385 & 10261 \\
\hline \multicolumn{7}{|c|}{ Case (b) } \\
\hline \multirow{4}{*}{38750} & \multirow{4}{*}{26750} & \multirow{4}{*}{1250} & \multirow{4}{*}{1000} & 4 & 55002 & 3181 \\
\hline & & & & 8 & 51983 & 4618 \\
\hline & & & & 12 & 49161 & 6103 \\
\hline & & & & 16 & 47046 & 7616 \\
\hline \multicolumn{7}{|c|}{ Case (c) } \\
\hline \multirow{4}{*}{31400} & \multirow{4}{*}{26250} & \multirow{4}{*}{1250} & \multirow{4}{*}{1000} & 4 & 47806 & 2765 \\
\hline & & & & 8 & 44683 & 3969 \\
\hline & & & & 12 & 41827 & 5193 \\
\hline & & & & 16 & 39702 & 6427 \\
\hline \multicolumn{7}{|c|}{ Case (d) } \\
\hline \multirow{4}{*}{27400} & \multirow{4}{*}{26250} & \multirow{4}{*}{1250} & \multirow{4}{*}{1000} & 4 & 43806 & 2533 \\
\hline & & & & 8 & 40683 & 3614 \\
\hline & & & & 12 & 37827 & 4696 \\
\hline & & & & 16 & 35702 & 5780 \\
\hline
\end{tabular}

Table 3. Net Annual Cash Flow, Pay Back Period and Cost of Drying for Case (a) $\left(\mathrm{P}_{\mathrm{i}}=\right.$ Rs.55100, $\mathrm{N}_{\mathrm{c}}=$ Number of Clear Days Per Year)

\begin{tabular}{|c|c|c|c|c|c|c|c|}
\hline $\mathbf{P}_{\mathrm{NPV}}$, (Rs.) & $\mathbf{i},(\%)$ & R, (Rs.) & $\mathbf{N}_{\mathrm{c}}$ & $M_{p}(\mathbf{k g})$ & CF (Rs.) & $\mathbf{n}_{\mathrm{p}},(\mathbf{y r s})$ & $\mathrm{C}_{\mathrm{g}},(\mathrm{Rs} / \mathrm{kg})$ \\
\hline \multirow{5}{*}{71043} & \multirow{5}{*}{4} & \multirow{5}{*}{4108} & 300 & 560 & 34000 & 2.23 & 7.34 \\
\hline & & & 270 & 504 & 30600 & 2.49 & 8.15 \\
\hline & & & 240 & 448 & 27200 & 2.81 & 9.17 \\
\hline & & & 210 & 392 & 23800 & 3.24 & 10.48 \\
\hline & & & 180 & 336 & 20400 & 3.82 & 12.23 \\
\hline \multirow{5}{*}{68234} & \multirow{5}{*}{8} & \multirow{5}{*}{6061} & 300 & 560 & 34000 & 2.27 & 10.82 \\
\hline & & & 270 & 504 & 30600 & 2.55 & 12.03 \\
\hline & & & 240 & 448 & 27200 & 2.91 & 13.53 \\
\hline & & & 210 & 392 & 23800 & 3.39 & 15.46 \\
\hline & & & 180 & 336 & 20400 & 4.05 & 18.04 \\
\hline \multirow[t]{5}{*}{65477} & 12 & 8129 & 300 & 560 & 34000 & 2.32 & 14.52 \\
\hline & & & 270 & 504 & 30600 & 2.62 & 16.13 \\
\hline & & & 240 & 448 & 27200 & 3.01 & 18.14 \\
\hline & & & 210 & 392 & 23800 & 3.54 & 20.74 \\
\hline & & & 180 & 336 & 20400 & 4.29 & 24.19 \\
\hline \multirow{5}{*}{63385} & \multirow{5}{*}{16} & \multirow{5}{*}{10261} & 300 & 560 & 34000 & 2.39 & 18.32 \\
\hline & & & 270 & 504 & 30600 & 2.71 & 20.36 \\
\hline & & & 240 & 448 & 27200 & 3.14 & 22.90 \\
\hline & & & 210 & 392 & 23800 & 3.74 & 26.18 \\
\hline & & & 180 & 336 & 20400 & 4.63 & 30.54 \\
\hline
\end{tabular}




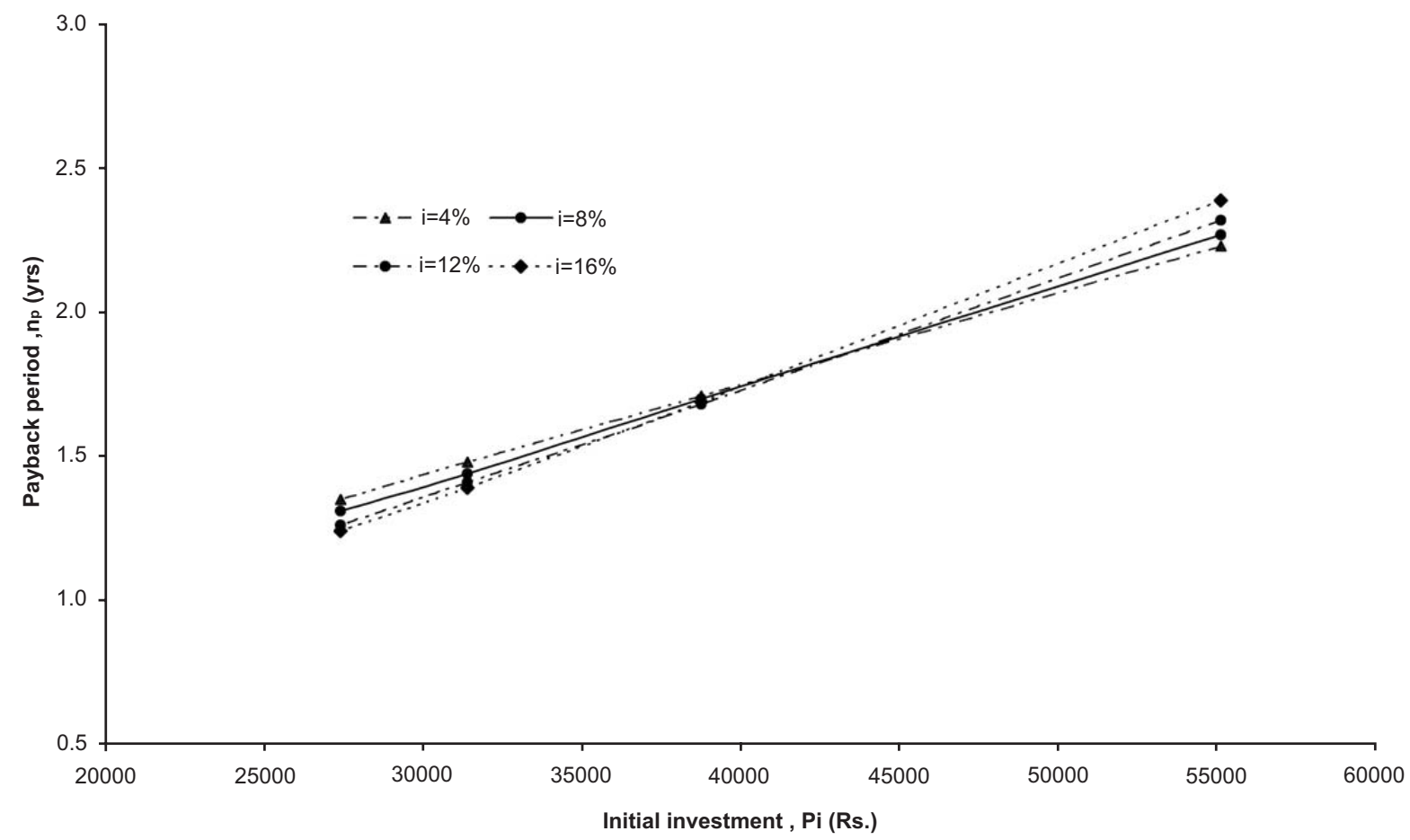

Fig. (2). Variation of payback period with net annual cash flow for different rate of interest for the dryer (Case :a).

The results for payback periods with various variable parameters such as annual cash flow, annual interest rate and initial investment have also been shown in Figs. (2-4).
From Table 3, it can be seen that the payback period increases with a decrease in the cash flow (annual income). This may happen due to reduction in number of clear days or

Table 4. Net Annual Cash Flow, Pay Back Period and Cost of Drying for Case $(b)\left(P_{i}=\right.$ Rs.38750, $N_{c}=$ Number of Clear Days Per Year)

\begin{tabular}{|c|c|c|c|c|c|c|c|}
\hline $\mathbf{P}_{\mathrm{NPV}}$, (Rs.) & $\mathrm{i},(\%)$ & R, (Rs.) & $\mathbf{N}_{\mathrm{c}}$ & $M_{p}(\mathbf{k g})$ & CF (Rs.) & $\mathrm{n}_{\mathrm{p}},(\mathrm{yrs})$ & $\mathrm{C}_{\mathrm{g}},(\mathrm{Rs} / \mathrm{kg})$ \\
\hline \multirow{5}{*}{55002} & \multirow{5}{*}{4} & \multirow{5}{*}{3181} & 300 & 560 & 34000 & 1.71 & 5.68 \\
\hline & & & 270 & 504 & 30600 & 1.90 & 6.31 \\
\hline & & & 240 & 448 & 27200 & 2.15 & 7.10 \\
\hline & & & 210 & 392 & 23800 & 2.47 & 8.11 \\
\hline & & & 180 & 336 & 20400 & 2.91 & 9.47 \\
\hline \multirow{5}{*}{51983} & \multirow{5}{*}{8} & \multirow{5}{*}{4618} & 300 & 560 & 34000 & 1.70 & 8.25 \\
\hline & & & 270 & 504 & 30600 & 1.90 & 9.16 \\
\hline & & & 240 & 448 & 27200 & 2.16 & 10.31 \\
\hline & & & 210 & 392 & 23800 & 2.50 & 11.78 \\
\hline & & & 180 & 336 & 20400 & 2.96 & 13.74 \\
\hline \multirow{5}{*}{49161} & \multirow{5}{*}{12} & \multirow{5}{*}{6103} & 300 & 560 & 34000 & 1.68 & 10.90 \\
\hline & & & 270 & 504 & 30600 & 1.89 & 12.11 \\
\hline & & & 240 & 448 & 27200 & 2.16 & 13.62 \\
\hline & & & 210 & 392 & 23800 & 2.51 & 15.57 \\
\hline & & & 180 & 336 & 20400 & 3.01 & 18.16 \\
\hline \multirow{5}{*}{47046} & \multirow{5}{*}{16} & \multirow{5}{*}{7616} & 300 & 560 & 34000 & 1.69 & 13.60 \\
\hline & & & 270 & 504 & 30600 & 1.90 & 15.11 \\
\hline & & & 240 & 448 & 27200 & 2.18 & 17.00 \\
\hline & & & 210 & 392 & 23800 & 2.56 & 19.43 \\
\hline & & & 180 & 336 & 20400 & 3.10 & 22.67 \\
\hline
\end{tabular}


Table 5. Net Annual Cash Flow, Pay Back Period and Cost of Drying for Case $(c)\left(P_{i}=R s .31400, N_{c}=\right.$ Number of Clear Days Per Year)

\begin{tabular}{|c|c|c|c|c|c|c|c|}
\hline $\mathbf{P}_{\mathrm{NPV}}$, (Rs.) & $\mathrm{i},(\%)$ & R, (Rs.) & $\mathbf{N}_{\mathrm{c}}$ & $M_{p}(\mathbf{k g})$ & CF (Rs.) & $\mathbf{n}_{\mathrm{p}},(\mathrm{yrs})$ & $\mathrm{C}_{\mathrm{g}},(\mathrm{Rs} / \mathrm{kg})$ \\
\hline \multirow{5}{*}{47806} & \multirow{5}{*}{4} & \multirow{5}{*}{2765} & 300 & 560 & 34000 & 1.48 & 4.94 \\
\hline & & & 270 & 504 & 30600 & 1.65 & 5.49 \\
\hline & & & 240 & 448 & 27200 & 1.86 & 6.17 \\
\hline & & & 210 & 392 & 23800 & 2.14 & 7.05 \\
\hline & & & 180 & 336 & 20400 & 2.51 & 8.23 \\
\hline \multirow{5}{*}{44683} & \multirow{5}{*}{8} & \multirow{5}{*}{3969} & 300 & 560 & 34000 & 1.44 & 7.09 \\
\hline & & & 270 & 504 & 30600 & 1.61 & 7.88 \\
\hline & & & 240 & 448 & 27200 & 1.83 & 8.86 \\
\hline & & & 210 & 392 & 23800 & 2.11 & 10.13 \\
\hline & & & 180 & 336 & 20400 & 2.50 & 11.81 \\
\hline \multirow{5}{*}{41827} & \multirow{5}{*}{12} & \multirow{5}{*}{5193} & 300 & 560 & 34000 & 1.41 & 9.27 \\
\hline & & & 270 & 504 & 30600 & 1.58 & 10.30 \\
\hline & & & 240 & 448 & 27200 & 1.80 & 11.59 \\
\hline & & & 210 & 392 & 23800 & 2.09 & 13.25 \\
\hline & & & 180 & 336 & 20400 & 2.49 & 15.45 \\
\hline \multirow{5}{*}{39702} & \multirow{5}{*}{16} & \multirow{5}{*}{6427} & 300 & 560 & 34000 & 1.39 & 11.48 \\
\hline & & & 270 & 504 & 30600 & 1.57 & 12.75 \\
\hline & & & 240 & 448 & 27200 & 1.79 & 14.35 \\
\hline & & & 210 & 392 & 23800 & 2.09 & 16.40 \\
\hline & & & 180 & 336 & 20400 & 2.51 & 19.13 \\
\hline
\end{tabular}

poor quality of drying of grapes. The same results have also been shown in Fig. (2). It is further noted that the effect of interest rate is significant on payback period at low annual cash flow. This effect is insignificant at higher annual cash flow as shown in Fig. (2).
The effect of annual interest rate on the payback period for four cases under study (Tables 3-6) has been shown in Fig. (3). This figure shows that payback period reduces significantly from case (a) to case (b) while in the (c) and (d)

Table 6. Net Annual Cash Flow, Pay Back Period and Cost of Drying for Case (d) $\left(P_{i}=\right.$ Rs.27400, $N_{c}=$ Number of Clear Days Per Year)

\begin{tabular}{|c|c|c|c|c|c|c|c|}
\hline $\mathbf{P}_{\mathrm{NPV}}$, (Rs.) & $\mathrm{i},(\%)$ & R, (Rs.) & $\mathbf{N}_{\mathrm{c}}$ & $M_{p}(\mathbf{k g})$ & CF (Rs.) & $\mathbf{n}_{\mathrm{p}},(\mathrm{yrs})$ & $\mathrm{C}_{\mathrm{g}},(\mathrm{Rs} / \mathrm{kg})$ \\
\hline \multirow{5}{*}{43806} & \multirow{5}{*}{4} & \multirow{5}{*}{2533} & 300 & 560 & 34000 & 1.35 & 4.52 \\
\hline & & & 270 & 504 & 30600 & 1.50 & 5.03 \\
\hline & & & 240 & 448 & 27200 & 1.70 & 5.65 \\
\hline & & & 210 & 392 & 23800 & 1.95 & 6.46 \\
\hline & & & 180 & 336 & 20400 & 2.29 & 7.54 \\
\hline \multirow{5}{*}{40683} & \multirow{5}{*}{8} & \multirow{5}{*}{3614} & 300 & 560 & 34000 & 1.31 & 6.45 \\
\hline & & & 270 & 504 & 30600 & 1.46 & 7.17 \\
\hline & & & 240 & 448 & 27200 & 1.66 & 8.07 \\
\hline & & & 210 & 392 & 23800 & 1.91 & 9.22 \\
\hline & & & 180 & 336 & 20400 & 2.26 & 10.76 \\
\hline \multirow{5}{*}{37827} & \multirow{5}{*}{12} & \multirow{5}{*}{4696} & 300 & 560 & 34000 & 1.26 & 8.39 \\
\hline & & & 270 & 504 & 30600 & 1.42 & 9.32 \\
\hline & & & 240 & 448 & 27200 & 1.61 & 10.48 \\
\hline & & & 210 & 392 & 23800 & 1.87 & 11.98 \\
\hline & & & 180 & 336 & 20400 & 2.22 & 13.98 \\
\hline \multirow{5}{*}{35702} & \multirow{5}{*}{16} & \multirow{5}{*}{5780} & 300 & 560 & 34000 & 1.24 & 10.32 \\
\hline & & & 270 & 504 & 30600 & 1.39 & 11.47 \\
\hline & & & 240 & 448 & 27200 & 1.59 & 12.90 \\
\hline & & & 210 & 392 & 23800 & 1.85 & 14.74 \\
\hline & & & 180 & 336 & 20400 & 2.21 & 17.20 \\
\hline
\end{tabular}




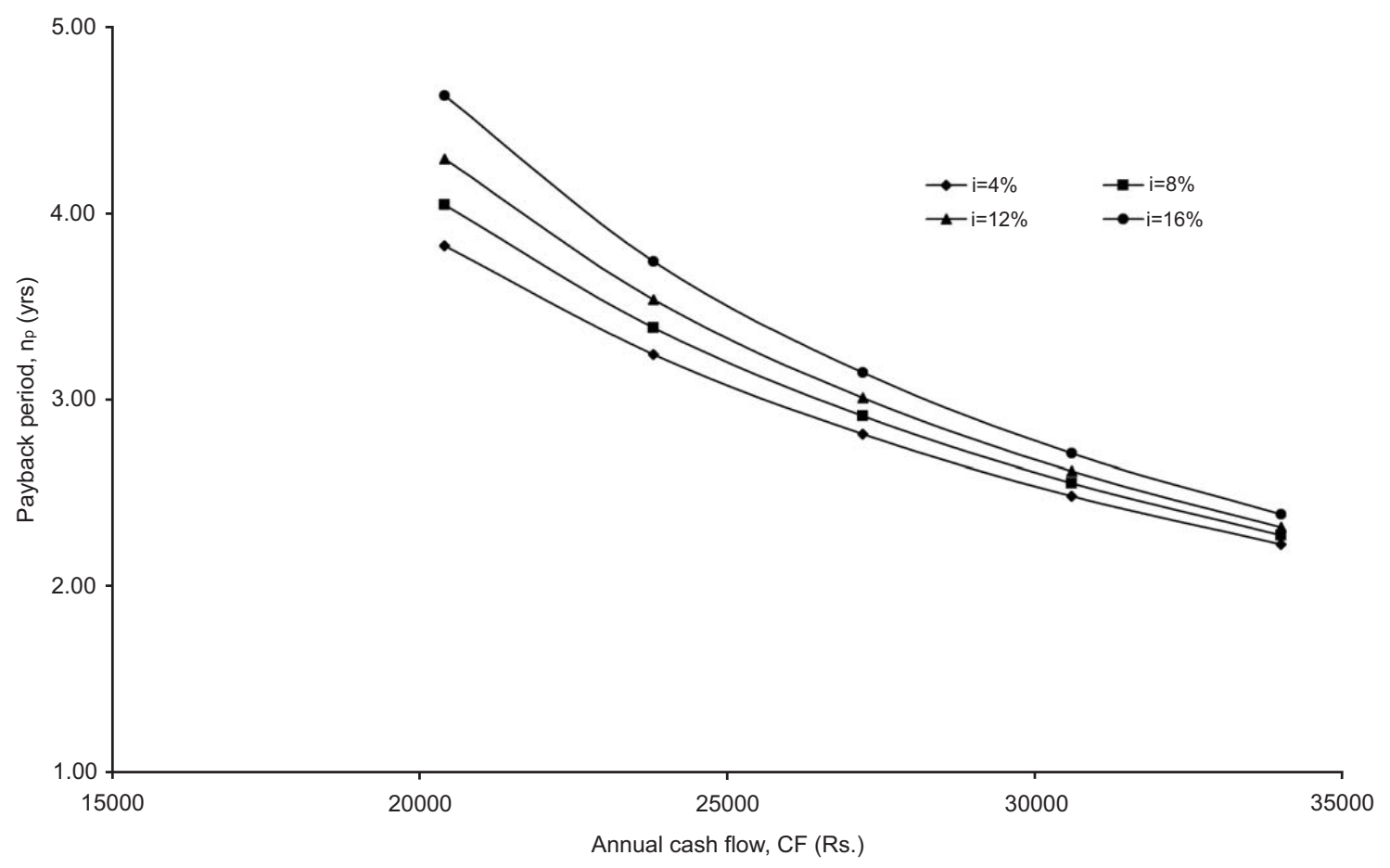

Fig. (3). Effect of annual interest rate on payback period for the hybrid PV/T greenhouse dryer.

cases, this reduction are marginal. Further, annual interest rate has marginal effect on payback period for all the cases.

The effect of initial investment on payback period for different rate of interest has been shown in Fig. (4). It is noted that for initial investment less or equal to the case (b), the results of payback period is opposite to the initial in- vestment more or equal to case (b). Fig. (4) suggests that for the present capacity of the dryer, the case (d) is the lowest initial investment with payback period of about 1.25 years.

The cost of drying of the grapes is lowest for initial investment for case $(\mathrm{d})\left(\mathrm{P}_{\mathrm{i}}=\right.$ Rs. 27,400$)$ i.e. Rs. 4.52 per $\mathrm{kg}$ (Table 6). This is the expected results due to lowest invest-

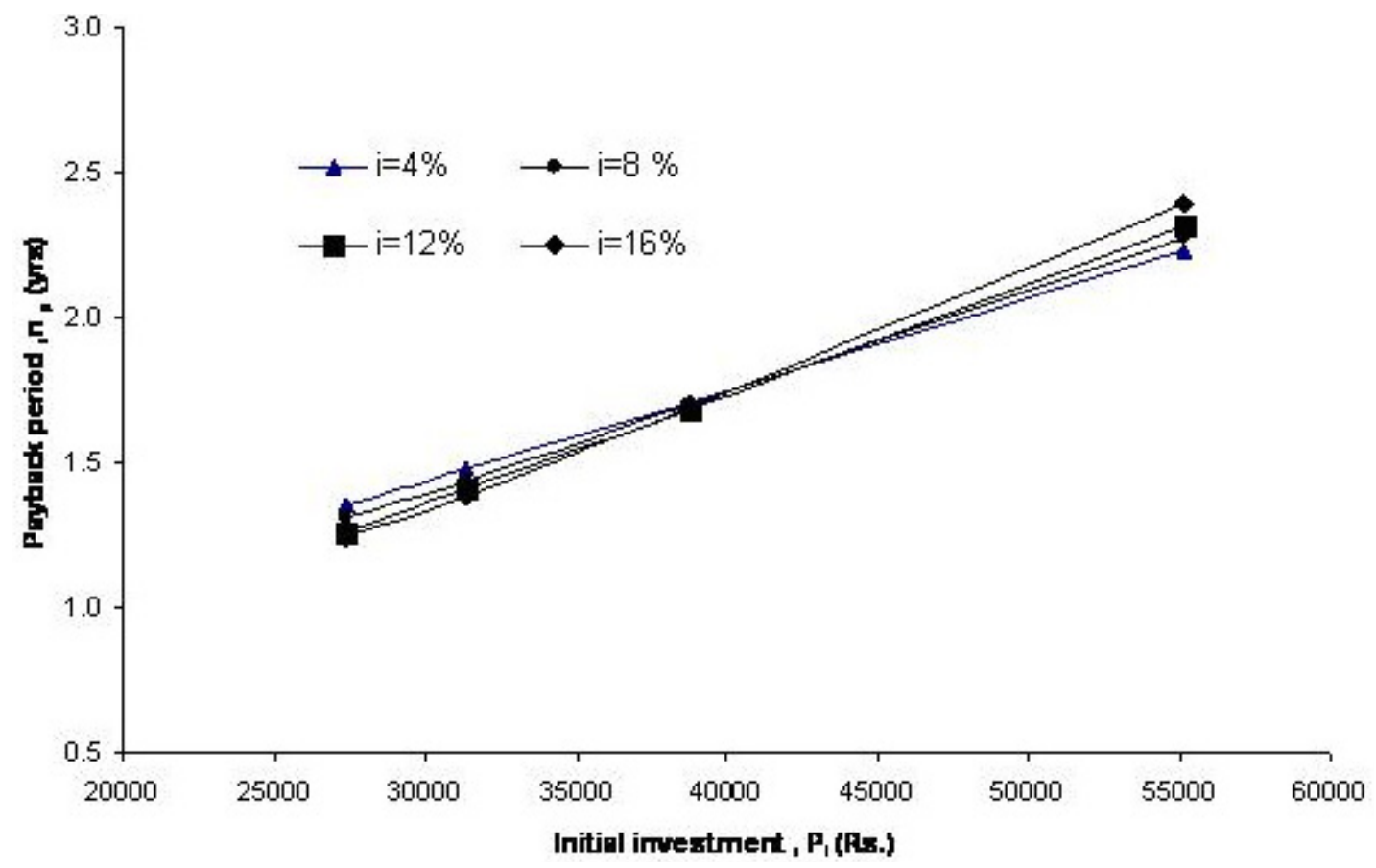

Fig. (4). Variation of payback period with initial investment of the dryer with different annual interest rate. 
ment at lowest interest rate (4\%). The cost of drying is maximum for maximum investment case (a) at maximum rate of interest (16\%) i.e. Rs. 30.54 per kg (Table 3).

\section{CONCLUSIONS}

From the present study, the following conclusions can be drawn:

1. The initial investment for case (d) (Rs. 27,400) gives the lowest payback period of about 1.25 years and

2. The cost of drying of the grapes is the lowest for initial investment for case (d) (Rs. 27,400) i.e. Rs. 4.52 per $\mathrm{kg}$.

\section{REFERENCES}

[1] Sodha MS, Chandra R., Pathak K, Singh NP, Bansal NK. Technoeconomic analysis of typical dryers. Energy Conversion and Management. 1991; 31(6): 509-13.
[2] Govind, Tiwari GN. Economic analysis of some solar energy systems. Energy Conversion Management 1984; 24(2):131-35.

[3] Hossain MA, Woods JL, Bala, BK. Optimisation of solar tunnel drier for drying of chilli without color loss. Renew Energy 2005; 30: 729-42

[4] Mumba J. Design and development of a solar grain dryer incorporating photovoltaic powered air circulation. Energy Conversion Management. 1996; 37(5): 615-21.

[5] Kumar A, Kandpal TC. Solar drying and $\mathrm{CO}_{2}$ emissions mitigation: potential for selected cash crops in India. Solar Energy. 2005; 78(2): 321-29.

[6] Barnwal P, Tiwari A. Design, Construction and Testing of Hybrid Photovoltaic Integrated Greenhouse Dryer. Int J Agric Res 2008; 3 (2): $110-20$

[7] Barnwal P, Tiwari A. Performance analysis of a Hybrid Photovoltaic-thermal (PV/T) Integrated Greenhouse Air Heater and Dryer. International Journal of Exergy (IJEX). 2008; Accepted.

[8] Tiwari GN. Solar Energy, Fundamentals, Design, Modelling and Applications, $1^{\text {st }}$ ed; Narosa Publishing House, New Delhi: India. 2002.

[9] Tiwari GN, Tiwari AK. Solar Distillation Practice for Water Desalination Systems. Anamaya Publishers. New Delhi : India, 2007.

(C) Barnwal and Tiwari; Licensee Bentham Open.

This is an open access article distributed under the terms of the Creative Commons Attribution License (http://creativecommons.org/licenses/by/2.5/), which permits unrestrictive use, distribution, and reproduction in any medium, provided the original work is properly cited. 